\section{Priority and the Raman effect}

SIR--Sachi Sri Kantha' once again raises the question of priority in the discovery in 1928 of light scattering with changed frequency, called the Raman effect or combinational scattering of light.

Kantha attempts to belittle the part played by Landsberg and Mandelstam in the discovery of the new phenomenon, although it is widely known that they discovered the same phenomenon at the same time independently of Raman, gave it a correct explanation but published their results ${ }^{2.3}$ later than Raman and Krishnan ${ }^{4.5}$.

A similar attempt to belittle the discovery of Landsberg and Mandelstam made necessary the publication of a note by the editors of the Journal of Raman Spectroscopy ${ }^{7}$. I also pointed out ${ }^{8}$ the full value and independence of Raman of the discovery made by Landsberg and Mandelstam.

In a speech", Raman said that "the line spectrum of the new radiation was first seen on the 28 February 1928 ".

In Mandelstam's letter to O. D. Khvolson, we read: "We first noted the appearance of the new lines on February 21,1928 . On a negative from an experiment of February 23-24 (exposure time 15 hours) the new lines were clearly visible." The photographs made from this film have been published ${ }^{8.10}$.

Landsberg and Mandelstam reported their discovery at the beginning of August 1928 at the sixth Congress of the Association of Russian Physicists. Twenty-one of the 400 participants were foreign scientists, among them Born, Brillouin, Darwin, Debye, Dirac, Phol, Pringsheim, Ph. Frank and Scheel. Accounts of the congress were published by Darwin in Nature ${ }^{11}$ and by Born in Naturwissenschaften". Darwin wrote: "Perhaps the most interesting work is that of Prof. Ioffe and that of Prof. Mandelstam and Landsberg. The latter described how they had independently discovered Raman phenomenon, the scattering of light with changed frequency."

Born wrote: "The effect discovered by Landsberg and Mandelstam in crystals is essentially identical to the effect observed by Raman and his colleague Krishnan in liquids. Russian physics can justly take pride in the fact that this important discovery was made by the Moscow researchers independently of the Indians and nearly simultaneously (February 20, 1928). This coincidence is one more demonstration of the international nature of our science, which now spans the entire world."

In the paper by A. Jayaraman and A. V. Ramdas ${ }^{13}$ devoted to the centenary of C. V. Raman, Indian physicists fairly wrote: "Really the Raman effect was independently discovered by Landsberg and Mandelstam in calcite and quartz crystals".

By 1930 more than 100 papers of different authors had been devoted to the investigation of this new phenomenon. It was well known by scientists that Raman and Krishnan in Calcutta and Landsberg and Mandelstam in Moscow had simultaneously and independently discovered the same remarkable phenomenon.

Justice demanded that the 1930 Nobel prize for physics for this discovery should be awarded to Raman, Landsberg and Mandelstam. Regrettably, that did not happen.

\section{P. N. Lebedev Physical Institute,}

Academy of Sciences USSR,

Leninsky Prosp. 53,

Moscow, USSR

1. Kantha, S.S. Nature 340, 672 (1989)

2. Landsberg G.S. \& Mandel'stam L.I. Naturwissenschaften 16, 557 (1928).

3. Landsberg G.S. \& Mandel'stam L.I. Zh.R.Ph. -Ch.O. 60 . 335 (1928)

4. Raman C.V. \& Krishnan K. S. Nature 121, 501 (1928)

5. Raman C.V. \& Krishnan K.S. Nature 121, 711 (1928)

6. Krishnan K.S. \& Shankar R.S. J. Raman Spect. 10. 1 (1981)

J. Raman Spectr. 10, No. 3 (1982).

8. Fabelinskii I.L. Optika i Spectroscopiya 55, 591 (1983)

9. Raman C.V. Indian J. Phys. 2, 383 (1928).

10. Fabelinskii I.L. Sov. Phys. Uspekhi 21, No. 9, September (1978).

11. Darwin C.G. Nature 122, 630 (1928).

12. Born M. Naturwissenschaften 16, 741 (1928).

13. Jayaraman A. \& Ramda A.K. Phys. Today 41, 56 part 1 (1988)

\section{To publish or not to publish}

SIR - In his leading article "Publicity without being damned" (Nature 343, 113; 1990), John Maddox leaves the impression that Physical Review Letters may have done the scientific community a disservice by publishing, without comment, the extraordinary results obtained by two Japanese scientists on the weight of gyroscopes in motion. I am not so sure. It could be argued that it is better to let the scientific community puzzle it out and subject the data to experimental verification without attempts to belittle or prejudice the interpretation of experiments that the referees were unable to fault. Nature would almost certainly have emerged with more dignity from the "celebrated case in 1988 " had it acted in the same way. Instead, it left a trail of unhappiness and discrimination that, in the final analysis, did not reflect much credit on anyone involved in the affair, although it may have provided some entertainment.

L. BRENT

St Mary's Hospital Medical School, Department of Immunology,

Wright-Fleming Institute,

London W2 1PG, UK
Schrödinger in pre-war Germany

SIR-May I add some background information to P. W. Atkins' review of W. Moore's biography of Schrödinger (Nature 341, 193-4; 1989) and its discussion by Popper (Nature 342, 337; 1989)?

In the spring of 1933, while I was a student at the University of Berlin taking the course in theoretical physics given by Schrödinger, I visited him to discuss a possible topic for a thesis. During that conversation, or soon thereafter, we both decided to leave Germany; he because he was disgusted with the political situation and I for even weightier reasons.

During our meeting, Schrödinger recounted an anecdote that David Hilbert, the great Göttingen mathematician, had told him. During the First World War, in the winter of 1916, the rector of the university invited the professors to gather for an important announcement. Hilbert thought, aha, he will tell us that we will get a goose for Christmas; but no, the rector announced that unrestricted U-boat warfare had been declared. Hilbert concluded: "I realized then that they were quite mad", adding "One has to imitate them in every detail." ("Man muss sie nachahmen bis ins kleinste.")

After Austria was annexed by Germany in 1938 and Schrödinger felt trapped in Graz, he probably remembered Hilbert's advice when he wrote to the senate of the university. In this letter he appears to me to be clearly imitating the 'joyous' Nazi style.

\section{Brookhaven National Laboratory}

MAURICE GOLDHABER Upton, New York 11973, USA

\section{Not so new}

SIR-You recently published a note by Tania Ewing about an Australian 'invention', the tamper-proof passport (Nature 342, 465; 1989). The fundamental method, however, of placing a picture on a passport by holographic means has been used here in Germany for our new IDcards and passports for at least two years.

HERBERT A. WARGENAU

Grassoweg 4B, D-1000 Berlin 39, FRG

\section{Carbon tax}

SIR-I wrote nominal not "normal carbon tax" in my letter (Nature 342, 730; 1989). Indeed, the very thrust of my calculation argues against a carbon tax, for at any reasonable level, such a tax would have far less effect in engendering fuel switching or energy economy than direct fiscal and investment measures.

MAXK. WALLIS

School of Mathematics,

University of Wales, Cardiff CF2 4AG, UK 